Research Article

\title{
Parents' knowledge, attitude, and practice on childhood immunization
}

\author{
Jolsna Joseph*, Vijayalakshmi Devarashetty, S. Narayana Reddy, M. Sushma
}

\begin{abstract}
Department of Pharmacology, Bangalore Medical College and Research Institute, Bengaluru, Karnataka, India
\end{abstract}

Received: 14 October 2015 Accepted: 14 November 2015

\author{
*Correspondence to: \\ Dr. Jolsna Joseph, \\ Email: jolsnajoseph87@gmail. \\ com
}
Copyright: (C) the author(s), publisher and licensee Medip Academy. This is an open- access article distributed under the terms of the Creative Commons Attribution Non- Commercial License, which permits unrestricted non- commercial use, distribution, and reproduction in any medium, provided the original work is properly cited.

\begin{abstract}
Background: The objective of present study was to determine the knowledge, attitude, and practices of parents regarding childhood immunization.

Methods: A cross-sectional survey was conducted in immunization clinic at Vanivilas hospital, a government tertiary care center (G) attached to Bangalore Medical College and Research Institute and a private pediatric clinic $(\mathrm{P})$ in Bengaluru. Data were collected from 200 parents/guardians (100 from each set up) using structured questionnaire administered by the investigators.

Results: Out of 200 parents surveyed, $172(86 \%)$ children were found to be fully immunized. The sickness of child was the most common cause $(67 \%)$ for missing vaccination. A statistically significant proportion of boys $(95 \%)$ were completely immunized as compared to girls $(84 \%, \mathrm{p}<0.01)$. Most of them knew that vaccination prevented some communicable diseases but were unaware as to which diseases they prevented and that the immunity is not life-long. Knowledge $(\mathrm{p}<0.004)$ and practice $(\mathrm{p}<0.001)$ of parents opting for optional vaccines were significantly higher in private setting compared to the government setting. All mothers opined that compliance to immunization schedule is important, had recommended vaccination to others and maintained a vaccination card. Gender of the child, birth order, mothers' educational status, monthly income of parents and religion significantly affected the vaccination status while mother's employment did not influence it.

Conclusion: Although childhood immunization practices and attitudes are satisfactory, majority do not have specific knowledge on vaccines and the duration of protection they offer. Socio-demographic factors had a significant influence on the immunization status. Hence, efforts should be focused on improving them also besides educating them about vaccines to improve their knowledge.

Keywords: Parents, Knowledge, Attitude, Practice, Children, Immunization status, Socio-demographic factors
\end{abstract}

\section{INTRODUCTION}

Immunization is the most cost-effective and the highestimpact health intervention which reduces hospitalization, treatment expenditure, and mortality. ${ }^{1}$ Despite the success of Expanded Program on Immunization (EPI) many vaccinepreventable diseases are remaining prevalent in developing countries like India (more than 5 lakh death annually in our country). ${ }^{2}$ According to the WHO, over 1.5 million children die from vaccine-preventable diseases globally and current immunization programs save more than 3.2 million lives each year and additional 1.7 million lives a year can be saved by full utilization of the existing vaccines. ${ }^{3}$

By increasing immunization coverage to above $80 \%$, disease transmission can be interrupted, whereby unimmunized children are also protected because of the herd immunity. ${ }^{4}$ To achieve this goal a full course of potent vaccines should be given at the right time.
EPI in India was revised and renamed as Universal Immunization Program (UIP), and it recommends that, bacille Calmette-Guerin (BCG), oral polio vaccine (OPV), triple antigen, measles and hepatitis $B$ vaccines should be included in the routine immunization schedule. The Indian Academy of Pediatrics has recommended other additional vaccines such as Haemophilus influenzae Type b (Hib), typhoid, hepatitis A, chickenpox and measles, mumps and rubella (MMR) as optional. At present, optional vaccines are being actively promoted by the family practitioners and pediatricians. Many of them are being promoted directly by the vaccine manufacturing companies through the distribution of printed educational materials to doctors and even advertisements in the media.

Acceptance of any vaccination program is largely dependent on knowledge and attitude of the mothers, ${ }^{5,6}$ provision of the services, ${ }^{6}$ density of health workers and the opportunity costs 
(such as lost earnings or time) incurred by parents. Therefore, it is important to consider whether or not resources should be invested in improving parent's knowledge and attitudes toward vaccination. Strategies based on the socio-cultural behavior of the community are important for success of any program. ${ }^{7}$ Since socio-economic, educational and cultural backgrounds differ by region, findings from one population cannot be generalized. Thus, it is imperative to do research into knowledge and attitudes of local population to improve services and to keep up the ongoing services. Hence, it seems appropriate to undertake the current study to gain good understanding of the knowledge, attitude and practice about immunization and also socio-demographic factors affecting immunization status.

\section{Objectives}

1. To assess parents' knowledge, attitude and practice about immunization

2. To evaluate socio-demographic factors affecting immunization status of the children.

\section{METHODS}

\section{Source of data}

1. Parents attending immunization clinic at Vanivilas Hospital attached to Bangalore Medical College and Research Institute, Bengaluru

2. Parents attending a private pediatric clinic for immunization of their children in Bengaluru.

\section{Methods of collection of data}

A. Study design: a cross-sectional, questionnaire-based study

B. Study period: August 2014-September 2014

C. Sample size: 200 parents/guardians.

\section{Methodology}

After explaining the study purpose and details thereof, those who agreed to participate in the study were interviewed by the investigators using a structured questionnaire including the demographic data of the child (age, gender, birth order) and of the parents (employment, educational level). Information regarding the vaccination status was obtained from the immunization card and on recall basis by the respondents in case of non-availability of the card.

Immunization status is defined as below: ${ }^{4}$

- Fully immunized: children who had received three doses of diphtheria, tetanus, pertussis (DPT), and OPV each and single dose of BCG and measles vaccine

- Partially immunized: those who had received one or more doses of these vaccines, but not all doses
- Unimmunized: those who had not received single dose of any vaccine.

Data were expressed as percentages or proportions. Tests of proportions were done with Chi-square wherever deemed necessary and a $\mathrm{p}<0.05$ was considered as statistically significant.

\section{RESULTS}

A total of 200 parents (100 in each set up) were included in this study. $86 \%$ of children were completely immunized for the age (Figure 1).

Among partially vaccinated (14\%), child being sick was the most cited reason for missing the vaccination followed by inconvenience, unawareness and inaccessibility to the health care services (Figure 2).

Among those who were interviewed only $28 \%$ of parents were aware that vaccines prevent some infectious diseases while $70 \%$ didnot know why they are given and $2 \%$ of them thought them as nutritional supplements (Figure 3).

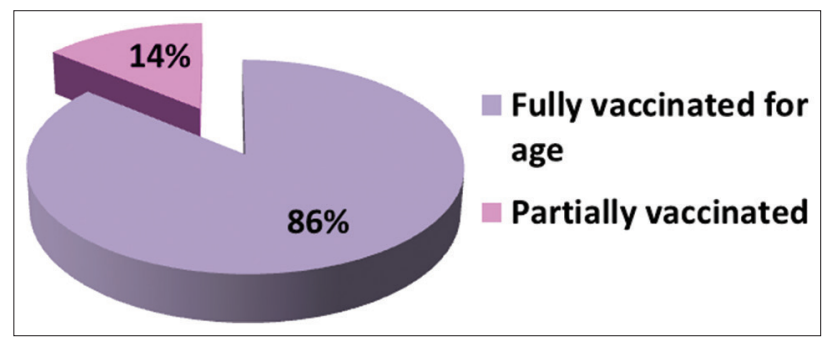

Figure 1: Immunization status of children.

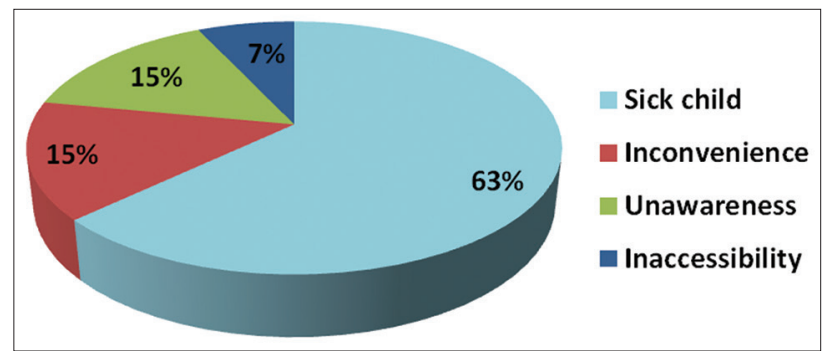

Figure 2: Reason for missing vaccination.

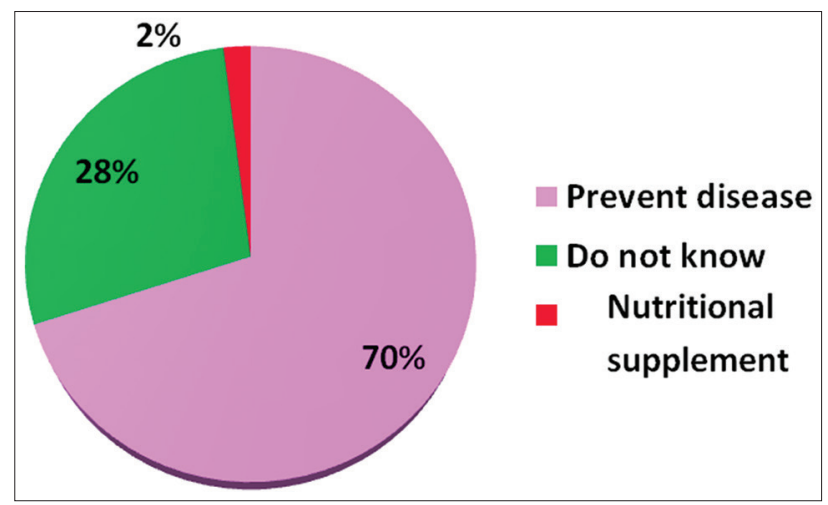

Figure 3: Vaccines are given because. 
$55 \%$ didnot know about the extent and duration of protection offered by the vaccines. $35 \%$ of parents had a misconception that all the vaccines provide $100 \%$ immunity life-long while $10 \%$ of the parents knew that their children can get infected with the same pathogen even after vaccination for the same.

The source of knowledge about vaccination was doctor for majority $(60 \%)$ of the parents followed by health workers, media and society (Figure 4).

$3 \%$ of parents were able to correctly match each vaccine against the diseases that prevent. $22 \%$ of parents responded correctly that OPV is given to prevent polio. Knowledge about other vaccines was still lower, measles $16 \%$, BCG 6\%, and DPT 6\% (Table 1).

The knowledge about the existence of optional vaccines was found to be significantly higher in parents who were attending private clinic compared to the government hospital (37\% vs. 19\%) and the same was reflected in practice as well (21\% vs. 6\%) (Tables 2 and 3).

$96 \%$ of the parents know that they have to vaccinate their children as per the scheduled date and believed that all the children in the community should receive vaccination. $96 \%$ of parents think that apart from routine immunization

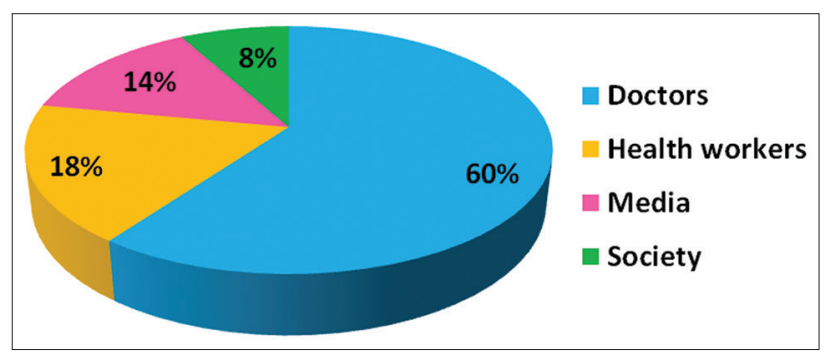

Figure 4: Source of knowledge about vaccination.

Table 1: Knowledge of parents about specific vaccines.

\begin{tabular}{|llc|}
\hline Vaccines & $\begin{array}{l}\text { Diseases they } \\
\text { prevent }\end{array}$ & $\begin{array}{c}\text { Percentage of } \\
\text { parents' answered } \\
\text { correctly (n=200) }\end{array}$ \\
\hline OPV & Polio & $22(44)$ \\
\hline Measles & Measles & $16(32)$ \\
\hline BCG & Tuberculosis & $6(12)$ \\
\hline DPT & $\begin{array}{l}\text { Diphtheria, } \\
\text { tetanus, pertussis }\end{array}$ & $6(12)$ \\
\hline
\end{tabular}

OPV: Oral polio vaccine, BCG: Bacille Calmette-Guerin

Table 2: Knowledge about optional vaccines.

\begin{tabular}{|lccccc|}
\hline Set up & Know & Don't know & Total & $\chi^{2}$ & p \\
\hline Government & 19 & 81 & 100 & 8.03 & $<0.05$ \\
\hline Private clinic & 37 & 63 & 100 & & \\
\hline Total & 56 & 144 & 200 & & \\
\hline
\end{tabular}

schedule their children should receive vaccination in pulse polio immunization (PPI) program. $85 \%$ of parents were aware of their children's next scheduled date for vaccination. Among various practices of parents, all the parents had their children vaccinated with BCG immediately after birth. All of them were found to be maintaining a vaccination card, and they had recommended vaccination to their friends and relatives (Table 4).

\section{Socio-demographic factors affecting immunization (Table 5)}

A statistically significant proportion of boys was completely immunized as compared to girls. Immunization status went on deteriorating as their birth order increased $(p<0.05)$ (Figure 5). There was a statistically significant positive association between immunization status of the children and mothers education level (Figure 6). However, there was no association with respect to working status of mothers. Monthly income of parents significantly affected the vaccination status. A number of partially vaccinated children was higher among parents having family income $<10,000$ Rs. per month (Figure 7). More number of Muslim children were partially immunized as compared to Hindus $(\mathrm{p}<0.05)$.

Table 3: Practice of giving optional vaccines.

\begin{tabular}{|lcccccc|}
\hline Set up & $\begin{array}{c}\text { Optional } \\
\text { vaccines }\end{array}$ & Total & $\chi^{2}$ & p \\
\cline { 2 - 5 } & Given & Not given & & & \\
\hline Government & 6 & 94 & 100 & 9.63 & $<0.05$ \\
\hline Private clinic & 21 & 79 & 100 & & \\
\hline Total & 27 & 173 & 200 & & \\
\hline
\end{tabular}

Table 4: Attitude and practices of parents.

\begin{tabular}{|lll|}
\hline $\begin{array}{l}\text { Do you think compliance to } \\
\text { immunisation schedule is } \\
\text { important (\%) }\end{array}$ & Yes (96) & No (4) \\
\hline $\begin{array}{l}\text { Do you think all children } \\
\text { should be vaccinated? (\%) }\end{array}$ & Yes (96) & No (4) \\
\hline $\begin{array}{l}\text { Is it required to vaccinate the } \\
\text { child during OPV campaigns } \\
\text { even though the child is fully }\end{array}$ & Yes (96) & No (4) \\
vaccinated (\%) & & \\
\hline $\begin{array}{l}\text { Do you know when is the } \\
\text { next vaccination date for } \\
\text { your child (\%) }\end{array}$ & Yes (85) & No (15) \\
\hline $\begin{array}{l}\text { Are you maintaining a } \\
\text { document for vaccination? (\%) }\end{array}$ & & \\
\hline $\begin{array}{l}\text { Whether the child was } \\
\text { vaccinated immediately after } \\
\text { birth (BCG)? (\%) }\end{array}$ & Yes (100) & \\
\hline $\begin{array}{l}\text { Have you recommended } \\
\text { vaccines to others? (\%) }\end{array}$ & Yes (96) & No (4) \\
\hline \begin{tabular}{l} 
OPV: Oral polio vaccine, BCG: Bacille Calmette-Guerin \\
\hline
\end{tabular}
\end{tabular}

OPV: Oral polio vaccine, BCG: Bacille Calmette-Guerin 
Table 5: Sociodemographic factors affecting immunisation status of children.

\begin{tabular}{|c|c|c|c|c|c|}
\hline \multirow[t]{2}{*}{ Affecting factors } & \multicolumn{3}{|c|}{ Immunisation status of children } & \multirow[t]{2}{*}{$\chi^{2}$} & \multirow[t]{2}{*}{ p value } \\
\hline & $\begin{array}{l}\text { Fully immunised } \\
\qquad n=172\end{array}$ & $\begin{array}{l}\text { Partially immunised } \\
\qquad \mathrm{n}=\mathbf{2 8}\end{array}$ & $\begin{array}{c}\text { Total } \\
\mathbf{n}=\mathbf{2 0 0}\end{array}$ & & \\
\hline \multicolumn{6}{|l|}{ Gender of the child } \\
\hline Male & 83 & 7 & 90 & 5.26 & $<0.05$ \\
\hline Female & 89 & 21 & 110 & & \\
\hline \multicolumn{6}{|l|}{ Birth order of the child } \\
\hline 1 st & 106 & 12 & 118 & 13.43 & $<0.05$ \\
\hline 2nd & 52 & 5 & 57 & & \\
\hline $3 r d$ & 16 & 9 & 25 & & \\
\hline \multicolumn{6}{|l|}{ Mother's educational status } \\
\hline Illiterate & 18 & 8 & 26 & 9.99 & $<0.05$ \\
\hline Primary & 28 & 7 & 35 & & \\
\hline Secondary and higher secondary & 102 & 11 & 113 & & \\
\hline Graduate & 19 & 2 & 21 & & \\
\hline Post graduate & 5 & 0 & 5 & & \\
\hline \multicolumn{6}{|l|}{ Occupation of mother } \\
\hline House wife & 156 & 27 & 183 & 1.017 & $>0.05$ \\
\hline Employed & 16 & 1 & 17 & & \\
\hline \multicolumn{6}{|l|}{ Monthly family income } \\
\hline$<10,000$ & 81 & 23 & 104 & 12.4 & $<0.05$ \\
\hline $10,000-20,000$ & 71 & 5 & 76 & & \\
\hline$>20,000$ & 20 & 0 & 20 & & \\
\hline \multicolumn{6}{|l|}{ Religion } \\
\hline Muslim & 54 & 21 & 75 & 19.58 & $<0.05$ \\
\hline Hindu & 118 & 7 & 125 & & \\
\hline
\end{tabular}

\section{DISCUSSION}

Childhood immunizations have a massive impact in prevention of many serious childhood infections. Despite having the world's largest immunization program, the incidence of under-five mortality in India is very high. Diseases like pneumonia, measles and pertussis that can be prevented by vaccination continue to be the major contributors. Knowledge and attitude of parents and sociocultural factors can influence the immunization status of children. ${ }^{3}$ In this study, we have tried to explore these factors which could influence the immunization status of children.

In the present study, $86 \%$ of the children were found to be fully vaccinated for the age and $14 \%$ were partially vaccinated. These study findings were very much similar to other studies conducted elsewhere in India (Maharashtra, Delhi) ${ }^{4,8}$ Majority of the children missed one or more doses of the vaccine because of their illness. Other reasons for missing doses of vaccine were inconvenience, unawareness and unable to access health care services. Similar findings were noted even in studies conducted across the globe. ${ }^{7,9}$ These findings suggest that greatest hindrance to get the child vaccinated is child being sick, which can be overcome by educating the parents that mild illness is not a reason to miss vaccinations. Child may still be vaccinated if he or she has a low-grade fever, cold, running nose, cough, ear infection or mild diarrhea so that they're protected against serious diseases. ${ }^{10}$

One of the important factors which can affect the parental practice is their knowledge regarding vaccination. ${ }^{11}$ A study conducted by Favin et al. ${ }^{12}$ showed that lack of knowledge about the importance of vaccines has been one of the main barrier to immunization. In this study, $70 \%$ of respondents believed that immunization prevents some infectious diseases, rest one-third of parents did not know this fact. $2 \%$ of parents had a misconception that it is a nutritional supplement which increases growth. Though vaccines per se are not nutritional supplements, they do indirectly facilitate growth and development of children. ${ }^{13}$

The high prevalence of vaccine-preventable diseases in a developing country like India highlights the need to effectively communicate essential information on vaccination to parents. Most mothers acknowledged that they came to know about vaccination from doctors. This is in line with the study conducted by Montasser et al. ${ }^{14}$ This finding suggests a huge responsibility of doctors not only in prescribing vaccines but also in educating parents 


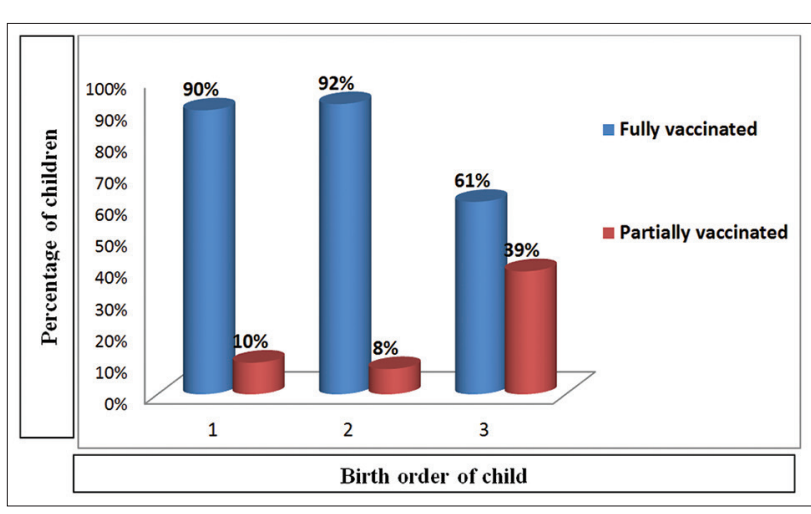

Figure 5: Immunization status according to birth order.

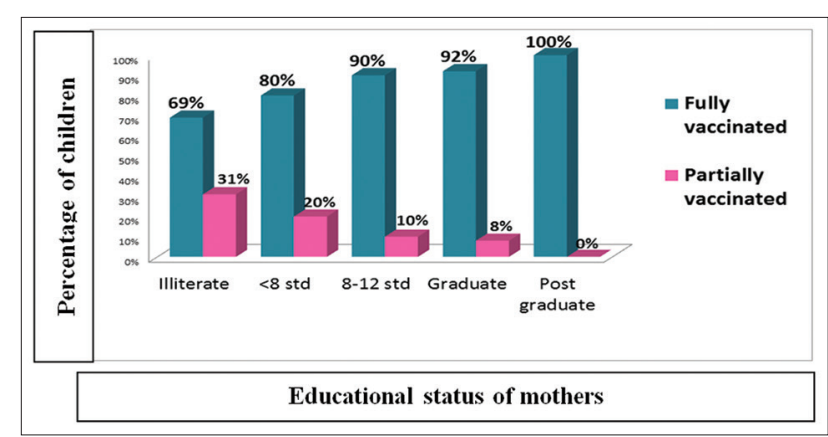

Figure 6: Children immunization status according to the level of education of mothers.

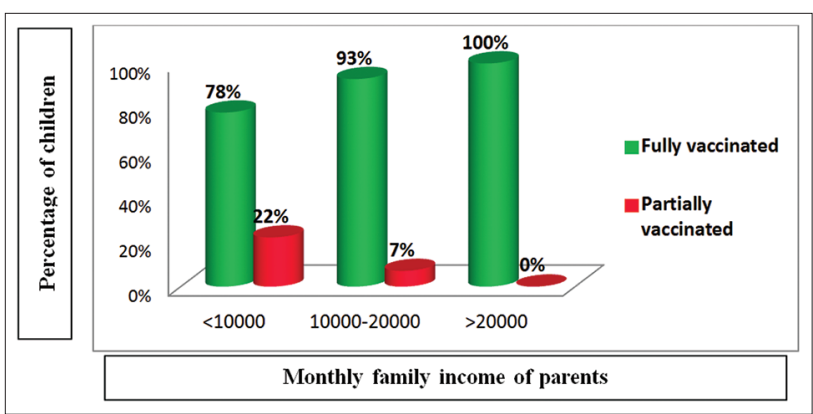

Figure 7: Distribution of children immunization status according to their monthly income.

toward better health care practices. This study has shown that parents obtained vaccine information from a multitude of other sources as well such as health workers, media and society. Hence, these means also prove pivotal in effectively disseminating information as it is in pulse polio program.

Very few parents responded correctly to the question about specific vaccines and the diseases they prevent. Only $22 \%$ of parents knew that OPV is given to prevent polio. Knowledge about diseases prevented by measles (16\%), BCG (6\%) and DPT (6\%) vaccines were found to be lower than that of OPV. However, only $10 \%$ of parents correctly answered the duration of protection offered by vaccines. Parents were better informed about OPV is due to wider dissemination of information about polio and its eradication through television, radio, street plays, involvement of the basic health care workers as volunteers who have better access to the community and endorsement of PPI by the celebrities. After all only 3\% of parents were able to match all the vaccines correctly against the disease they prevent.

The lacunae of knowledge noted in the present study among parents' calls for active intervention for better acceptance of the vaccination program as some studies have shown that provision of information about a disease, its adverse sequelae and the effectiveness of the vaccine have been shown to improve uptake of vaccines. ${ }^{14}$

The Indian Academy of Pediatrics recommends three doses of Hib, pneumococcal conjugate vaccine, Rotavirus and hepatitis B vaccine, 1 dose of MMR and varicella zoster virus before 18 months of age. Hib and hepatitis $B$ vaccines have been included in UIP recently. Vaccines which are not included in UIP are considered optional vaccines. Free vaccines in the government set up are limited to that included in UIP. In this study, $37 \%$ of parents who attended private clinic were found to be aware of optional vaccines compared to $19 \%$ of parents who attended government hospitals. This knowledge has translated into practice as a higher proportion of parents $(21 \%)$ who attended private clinic had opted for optional vaccines as compared to those who attended (6\%) government hospital. This trend may be due to effective counseling and active promotion of optional vaccines by private practitioners. Other factors to consider for such contrast are; as the latter provide vaccines included in UIP only and less affordability of parents attending the government hospital. Higher acceptance of optional vaccines in the private set up was also shown in a study by Manthiram et al. in South India. ${ }^{15}$

Parents attitude has a significant impact on vaccination status of children. ${ }^{16}$ Almost all of the parents believe that compliance to the immunization schedule is important $(96 \%)$, and this percentage is higher compared to a study done by Bernsen et al. in the United Arab Emirates. ${ }^{17}$ In this study, $96 \%$ of parents found to believe that all the children in the community should receive vaccination which was higher compared to a study conducted at Libya. ${ }^{7}$ This difference could be due to difference in socio-cultural background of the study population. $85 \%$ of parents were aware of the next scheduled date for immunization for their children. Such display of positive attitude by the parents is a welcome and should be encouraged.

With the aim of interrupting the transmission of wild poliovirus by exposing children to the vaccine virus; the Government of India launched the PPI program on a country-wide basis. ${ }^{18}$ PPI consists of simultaneous, mass administration of OPV on a single day to all children aged below 5 years on two National Immunization Days. ${ }^{19}$ In the present study, $94 \%$ of the parents believe that their children should receive vaccination in PPI campaigns in addition to routine schedule. 
Good parental practice of immunization will reduce the incidence of infectious diseases. ${ }^{20}$ In the present study, all children were found to be immunized with BCG at birth. In India, BCG is given within 1 week of childbirth. In our study, all the interviewed parents had institutional deliveries, where administration of BCG before discharging the mother is a norm. While their stay in the hospital, they were given printed vaccination card depicting the vaccines to be given against the recommended age. It is a routine practice that, doctor and other health care workers further emphasize the compliance to vaccination schedule before the mother is discharged. All these factors would explain 100\% coverage of BCG.

The vaccination card is a very important document for the parents to determine which vaccine is due for their child and the provider to check their child's immunization status. Odusanya $\mathrm{O} \mathrm{O}$ et al. have reported that if parents could maintain a vaccination card, the child is more likely to get fully vaccinated. ${ }^{6}$ In this study, though vaccine card was maintained by all of them (100\%), some (14\%) missed out one or more doses which could be due to other reasons mentioned earlier.

Studies have shown that socio-cultural factors have a huge influence on immunization status of children. Significant difference (92\% vs. $81 \%$ ) was observed between immunization status of boys and girls. This is in agreement with other studies conducted in other parts of the country. ${ }^{21,22}$ It may be attributable to patriarchal mindset and priority given to male child. Birth order of child significantly affected their vaccination status, as birth order increased the vaccination status deteriorated. Studies from other parts of the country also showed similar finding. ${ }^{22,23}$ Mothers are often strongly influential in the vaccination of their children. It is, therefore, important to ensure that health interventions for promoting childhood vaccinations should tackle maternal concerns and barriers. In the present study, children of literate mothers were found to have more chance of completing the immunization as per the schedule. It is in agreement with the findings of a study done by Malkar et al. in India. ${ }^{4}$ Another study done by Prislin et al. concluded that a mother, who believes immunization offers protection against serious diseases, is likely to have her child immunised. ${ }^{24}$ The present study also observed that irrespective of the working status of mothers, majority of the children completed their vaccination as per the schedule similar to a study conducted by Bofarraj. ${ }^{7}$

Parental income can be another factor which can affect immunization status of children. In this study, it was found out that as the family income increased proportion of children reaching fully vaccinated status is also increased. Children from those families having less income were less likely to be fully vaccinated. This could be because, the low-income group prioritize their time for earning for their family than on preventive health care and also due to poor education level. ${ }^{7}$
Religious background of parents also can influence the vaccination status of children. Immunization of Hindu children was more often found to be completed than their Muslim counterparts which are in line with the findings of Malkar et al. in India. ${ }^{4}$

\section{CONCLUSION}

Majority of parents' knew the importance of vaccination. Positive attitude toward immunization and satisfactory practices were noted in this study group. Knowledge about and practice of giving optional vaccines were higher in the private set up. Gender of the child, birth order, mothers' educational status, monthly income of parents and religion were the major factors determining vaccination status of children.

Insufficient knowledge of the parents call for educational programs on pediatric immunization targeting the entire population with a special emphasis on maternal motivation and improving socio-economic status for the success of the UIP in our country.

Funding: No funding sources

Conflict of interest: None declared

Ethical approval: The study was approved by the Institutional Ethics Committee

\section{REFERENCES}

1. Caingles SE, Lobo JJ. Survey on the knowledge, attitudes and practices of parents in Barangay 8a, District 1, Davao city regarding their children's immunization. PIDSP J. 2011;12(1):46-53.

2. Vashishtha VM, Kumar P 50 years of immunization in India: progress and future. Indian Pediatr. 2013;50(1):111-8.

3. Al-Zahrani JO. Knowledge, attitude and practice of parents towards childhood vaccination. Majmaah J Health Sci. 2013;1(1):30-8.

4. Malkar VR, Khadilakar H, Joge US, Choudhari SG. Assessment of sociodemographic factors affecting immunization status of children in age group of 12-23 months in a rural area. Indian Med Gazette. 2013; 147(5):164-70.

5. Rahman M, Obaida-Nasrin S. Factors affecting acceptance of complete immunization coverage of children under five years in rural Bangladesh. Salud Publica Mex. 2010;52(2):134-40.

6. Odusanya OO, Alufohai EF, Meurice FP, Ahonkhai VI. Determinants of vaccination coverage in rural Nigeria. BMC Public Health. 2008;8:381.

7. Bofarraj MA. Knowledge, attitude and practices of mothers regarding immunization of infants and preschool children at Al-Beida city, Libya. JDUHS. 2007;1(1):15-9.

8. Gupta RK, Pandey A. Status of children in East Delhi: care during delivery, immunization and occurrence of some acute diseases. Indian J Community Med. 2007;32(1):21-4.

9. Nisar N, Mirza M, Qadri MH. Knowledge, attitude and practices of mothers regarding immunization of one year old child at Mawatch Goth, Kemari town, Karachi, Pakistan. Pak J Med Sci. 2010;26(1):183-90.

10. Available from: http://www.cdc.gov/mmwr/pdf/rr/rr6002. pdf. Accessed 12 Augeuest 2015. 
11. Awadh AI, Hassali MA, Al-lela OQ, Bux SH, Elkalmi RM, Hadi H. Immunization knowledge and practice among Malaysian parents: a questionnaire development and pilottesting. BMC Public Health. 2014;14:1107.

12. Favin M, Steinglass R, Fields R, Banerjee K, Sawhney M. Why children are not vaccinated: a review of the grey literature. Int Health. 2012;4:229-38.

13. Anekwe TD, Kumar S. The effect of a vaccination program on child anthropometry: evidence from India's Universal Immunization Program. J Public Health (Oxf). 2012;34(4):489-97.

14. Montasser NA, Helal RM, Eladawi N, Mostafa E, Rahman FA, Saad M, et al. Knowledge, attitude and beliefs of caregivers of children below 2 years of age towards Immunization. Br J Med Med Res. 2014;4:2757-67.

15. Manthiram K, Blood EA, Kuppuswamy V, Martins Y, Narayan A, Burmeister K, et al. Predictors of optional immunization uptake in an urban south Indian population. Vaccine. 2014;32(27):3417-23. Lahariya C. A brief history of vaccines \& vaccination in India. Indian $\mathrm{J}$ Med Res. 2014;139(4):491-511.

16. Gust DA, Strine TW, Maurice E, Smith P, Yusuf H, Wilkinson $\mathrm{M}$, et al. Underimmunization among children: effects of vaccine safety concerns on immunization status. Pediatrics. 2004;114(1):e16-22.

17. Bernsen RM, Al-Zahmi FR, Al-Ali NA, Hamoudi RO, Ali NA, Schneider J, et al. Knowledge, attitude and practice towards immunizations among mothers in a traditional city in the United Arab Emirates. J Med Sci. 2011;4(3):114-21.
18. Park K. Epidemiology of communicable diseases. Park's Text Book of Preventive and Social Medicine. 20th Edition. Jabalpur: Banarsidas Bhanot; 2009: 183.

19. Joseph N, Subba Sh, Nelliyanil M, Kotian S, Haridath A, N K, et al. A study of the knowledge and attitude towards pulse polio immunization in semi urban areas of South India. Australas Med J 2011;4:81-6.

20. Al-Lela OQ, Bahari MB, Al-Qazaz HK, Salih MR, Jamshed SQ, Elkalmi RM. Are parents' knowledge and practice regarding immunization related to pediatrics' immunization compliance? A mixed method study. BMC Pediatr. 2014;14:20.

21. Available at http://www.ncbi.nlm.nih.gov/pmc/articles/ PMC3762848/pdf/pone.0073102.pdf. Accessed 12 August 2015.

22. Mathew JL. Inequity in childhood immunization in India: a systematic review. Indian Pediatr. 2012;49(3):203-23.

23. Sharma S. Socioeconomic factors of full immunisation coverage in India. World J Vaccin. 2013; 3:102-10.

24. Prislin R, Dyer JA, Blakely CH, Johnson CD. Immunization status and sociodemographic characteristics: the mediating role of beliefs, attitudes, and perceived control. Am J Public Health 1998;88:1821-6.

Cite this article as: Joseph J, Devarashetty V, Reddy SN, Sushma M. Parents' knowledge, attitude and practice on childhood immunization. Int J Basic Clin Pharmacol 2015;4:1201-7. 